\title{
The YJL185C, YLR376C and YJR129C genes of Saccharomyces cerevisiae are probably involved in regulation of the glyoxylate cycle
}

\author{
Ewa Boniewska-Bernacka ${ }^{1 \bowtie}$, Robert Wysocki², Renata Grochowalska ${ }^{3}$, \\ Beata Machnicka ${ }^{3}$, Stanisław Ułaszewski ${ }^{2}$ and Tadeusz Lachowicz \\ ${ }^{1}$ Department of Biotechnology and Molecular Biology, University of Opole, Poland; ${ }^{2}$ Institute of Genetics and \\ Microbiology, Wroclaw University, Wroctaw, Poland; ${ }^{3}$ Institute of Biotechnology and Environmental Protection,

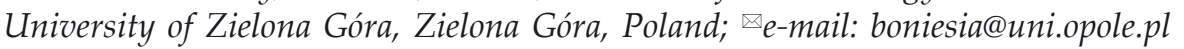

Received: 20 February, 2006; revised: 16 October, 2006; accepted: 18 October, 2006 available on-line: 04 December, 2006

\begin{abstract}
The ER24 aci (acidification) mutant of Saccharomyces cerevisiae excreting protons in the absence of glucose was transformed with a multicopy yeast DNA plasmid library. Three different DNA fragments restored the wild-type phenotype termed $\mathrm{Aci}^{-}$because it does not acidify the complete glucose medium under the tested conditions. Molecular dissection of the transforming DNA fragments identified two multicopy suppressor genes YJL185C, YJR129C and one allelic YLR376C. Disruption of either of the three genes in wild-type yeast strain resulted in acidification of the medium ( $\mathrm{Aci}^{+}$phenotype) similarly to the original ER24 mutant. These data indicate the contribution of the ER24 gene product Ylr376Cp and of the two suppressor gene products Yj1185Cp and Yjr129Cp to a complex regulation of the glyoxylate cycle in yeast.
\end{abstract}

Keywords: Saccharomyces cerevisiae, acidification mutants, multicopy suppressor, glyoxylate cycle, yeast

\section{INTRODUCTION}

The yeast Saccharomyces cerevisiae growing on complete Kok medium containing glucose and bromocresol purple forms gray colonies on a violet background (Kok et al., 1975; Goffeau, 2000). At least 17 non-allelic single-gene aci (acidification) mutants whose colonies are surrounded by a yellow acidic zone have been isolated. This determined the $\mathrm{Aci}^{+}$mutant phenotype (Gonchar et al., 1990; Boniewska-Bernacka et al., 1998; Grochowalska et al., 2003). The mutant cells show abrupt proton liberation when suspended in distilled water. Gas chromatography analysis indicated that the Krebs/glyoxylate cycle intermediates are the proton carriers excreted in the medium and that these intermediates preexisted in the cells at the start of the acidification test (Machnicka et al., 2004). We report here a detailed study of the ER24 mutant that belongs to the complementation group III of the aci mutants (Grochowalska et al., 2003).

\section{MATERIAL AND METHODS}

Yeast strains and plasmids. Strains and plasmids used in this work are shown in Table 1 and Table 2, respectively. For cloning we used Escherichia

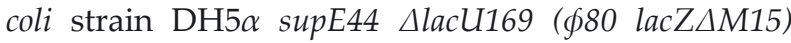
hsdR17 recA1 endA1 gyrA96 thi1 relA1 (Hanahan, 1983).

Media. YPD (bactopeptone 1\%, yeast extract $1 \%$, dextrose $2 \%$ ), mineral Go medium (yeast nitrogen base $0.67 \%$, glucose $2 \%$ ), Kok screening medium (Kok et al., 1975) (glucose 1\%, bactopeptone 1\%, yeast extract $2 \%$, bromocresol purple $10 \mathrm{mg} / \mathrm{ml}$ ), LB (yeast extract $1 \%$, bactotryptone $1 \%$, glucose $0.1 \%$, $\mathrm{NaCl}$ 0.5\%) after Sambrook et al. (1989), Semi synthetic medium of Sigler et al. (1981). The plating media contained 2\% bactoagar. Amino acids were added, if necessary.

Growth conditions. The strains were held on slants at $4^{\circ} \mathrm{C}$ and cultivated at $28^{\circ} \mathrm{C}$ in liquid medium with shaking. The acidifying mutants were screened 
Table 1. Strains used in this work

\begin{tabular}{|c|c|c|}
\hline Strain of Saccharomyces cerevisiae & Markers or description & Origin \\
\hline $\mathrm{D} 273-10 \mathrm{~B} / \mathrm{A}_{1}$ & MATa met6 & $\begin{array}{l}\text { Grenson M., Université Libre de Bruxelles, } \\
\text { Belgium }\end{array}$ \\
\hline F87-24B & MATa his3 & $\begin{array}{l}\text { Grenson M., Université Libre de Bruxelles, } \\
\text { Belgium }\end{array}$ \\
\hline ER24 & MAT $\alpha$ met6 $\triangle$ ura3 aci1 & this study \\
\hline tER24-1 & MATa met6 ACI1 & ER24 transformant \\
\hline tER24-2 & MAT $\alpha$ met6 ACI1 & ER24 transformant \\
\hline tER24-3 & MATa met6 ACI1 & ER24 transformant \\
\hline YJL185C & $\begin{array}{l}\text { MATa ura3-52 his3_1 leu2-3_112 trp1-289 } \\
\text { YJL185c::KANMX4 }\end{array}$ & Disruptant of gene YJL185C (Euroscarf) \\
\hline YLR376C & $\begin{array}{l}\text { MAT a his } 3 \Delta 1 \text { leu } 2 \Delta 0 \text { met } 15 \Delta 0 \\
\text { ura3 } \Delta 0 \text { YLR376c::kanMX4 }\end{array}$ & Disruptant of gene $Y L R 376 C$ (Euroscarf) \\
\hline YJR129C & $\begin{array}{l}\text { MAT a his3 } \Delta 1 \text { leu } 2 \Delta 0 \text { met } 15 \Delta 0 \\
\text { ura3 } \Delta 0 \text { YJL129c::kanMX4 }\end{array}$ & Disruptant of gene YJR129C (Euroscarf) \\
\hline
\end{tabular}

on Kok medium as forming colonies surrounded by yellow zones (Kok et al., 1975).

Proton extrusion. Proton extrusion by yeast cells was estimated according to Haworth et al. (1991) with a modification by Sigler et al. (1991) on a computer-linked pH-meter (Radomski et al., 1995).

Genetic manipulations. Strain construction, crossing and tetrad analysis were carried out by standard genetic techniques (Sherman et al., 1987). Tetrads were dissected with a Singer micromanipulator. For chromosomal mapping, the mutants were crossed with a collection of 16 cir $^{0}$ tester strains, each containing plasmid DNA integrated near the centromere of suitable chromosomes (Wakem \& Sherman, 1990).

Cloning strategies. aci strains with the $\Delta$ ura3 disruption (introduced by recombination)

Table 2. Plasmids used in this work

\begin{tabular}{|c|c|c|}
\hline Plasmid & Characterization & Origin \\
\hline pFL44L & Multicopy, shuttle vector, $A m p^{R} U R A 3$ & Bonneaud et al. (1991) \\
\hline pFL44S & Multicopy, shuttle vector, $A m p^{R} U R A 3$ & Bonneaud et al. (1991) \\
\hline pFL38 & Centromeric vector, $\mathrm{Amp}^{\mathrm{R}} U R A 3$ & Bonneaud et al. (1991) \\
\hline pER24-1/No1 & $\begin{array}{l}\text { pFL44L with a } 3638 \text { bp fragment of chromosome X comprising genes YJL185C, } \\
\text { YJL184W }\end{array}$ & this study \\
\hline pER24-3/No1 & $\begin{array}{l}\text { pFL44L with } 5964 \text { bp fragment of chromosome XII with genes } t K(U U U) L \text {, } \\
\text { FBP1, YLR376C, YLR375W(STP3), YLR374C, VID22 }\end{array}$ & this study \\
\hline pER24-3/No2 & $\begin{array}{l}\text { Isolated from yeast gene bank plasmid pFL44L with } 5415 \text { bp fragment of } \\
\text { chromosome X with genes YJR128W, SNR3, YJR129C, STR2 }\end{array}$ & this study \\
\hline p24-1A & $\begin{array}{l}\text { Constructed from plasmid pER24-1/No1 by deletion of SalI-SalI fragment (959 } \\
\text { bp), includes gene YJL184W }\end{array}$ & this study \\
\hline p24-1B & $\begin{array}{l}\text { Construct plasmid pER24-1/No1 by deletion of PvuII-PvuII fragment (1720 bp), } \\
\text { includes gene } Y J L 185 C\end{array}$ & this study \\
\hline p24-3A & $\begin{array}{l}\text { Construct plasmid pER24-3/No1 by deletion of BamHI-BamHI fragment (1926 } \\
\text { bp), includes gene YLR374C }\end{array}$ & this study \\
\hline p24-3B & $\begin{array}{l}\text { KpnI-XbaI fragment ( } 2521 \mathrm{bp}) \text { from plasmid pER 24-3/No1 ligated to pFL44S, } \\
\text { includes gene } F B P 1\end{array}$ & this study \\
\hline p24-3C & $\begin{array}{l}\text { Construct BamHI-BamHI fragment (1926 bp) from plasmid pER24-3/No1 li- } \\
\text { gated with pFL44S, includes gene YLR376C }\end{array}$ & this study \\
\hline p24-3D & $\begin{array}{l}\text { Construct XbaI-HindIII fragment ( } 2505 \mathrm{bp} \text { ) from plasmid pER24-3/No1 ligated } \\
\text { with pFL44S, include genes STP3 and YLR374C }\end{array}$ & this study \\
\hline p24-3E & $\begin{array}{l}\text { Construct plasmid pER24-3/No2 by deletion of PvuII-PvuII fragment (1740 bp), } \\
\text { includes gene YJR128W }\end{array}$ & this study \\
\hline p24-3F & $\begin{array}{l}\text { Construct plasmid pER24-3/No2 by deletion of SphI-SphI fragment (2121 bp), } \\
\text { includes gene STR2 }\end{array}$ & this study \\
\hline p24-3G & $\begin{array}{l}\text { Construct BamHI-XhoI fragment ( } 1857 \mathrm{bp}) \text { from plasmid pER24-3/No2 ligated } \\
\text { with pFL44S, includes gene YJR129C }\end{array}$ & this study \\
\hline
\end{tabular}


were transformed with a yeast DNA library on the plasmid shuttle vector pFL44L (Bonneaud et al., 1991) using the lithium acetate procedure (Gietz \& Woods, 1998). The transformants selected for uracil prototrophy were screened for the $\mathrm{Aci}^{-}$phenotype on Kok medium.

Plasmid DNA was isolated from the yeast transformants and cloned in Escherichia coli. Restriction fragments from the cloned plasmids were isolated from low melting point agarose gel (Sambrook et al., 1989). Sequencing of about 100 nucleotides from the ends of yeast DNA fragments was carried out using the dideoxy chain termination procedure (Sanger et al., 1977).

Physical mapping of the plasmid DNA isolated from the transformants was performed according to the recommendations of Sherman et al. (1987).

The stability of plasmids in the transformants was tested by mitotic segregation. Yeast cells were serially cultivated for about 24 generations in complete YPD medium. After each passage a sample of about one hundred cells was plated on Kok medium and the fraction of $\mathrm{Aci}^{+}$colonies was determined (Kok et al., 1975).

\section{RESULTS}

\section{Genetics of the aci1 mutant ER24}

The mutant ER24 excreted acids during growth on glucose complete medium. It was unable to grow on glycerol, acetate, ethanol, or citrate and this feature co-segregated 2:2 with the $\mathrm{Aci}^{+}$character in 20 tetrads from a cross with the isogenic wildtype stain F87-24B (not shown).

The mutated genes responsible for acidification are recessive, as the diploid obtained from a cross to the isogenic strain F87-24B MATa his3 did not excreting acids. The inability to grow on glycerol is not caused by cytochrome defects which were present (Claisse et al., 1992).

In order to localize the acil gene causing the ER24 phenotype, the Sherman collection of $\mathrm{cir}^{0}$ tester strains for each chromosomes of both MAT $\alpha$ and $M A T a$ were crossed to the ER24 mutant in which ura3 was introduced by recombination (Wakem \& Sherman, 1990).

The diploids obtained were grown in complete YPD medium for at least 24 generations and an increased frequency of $\mathrm{Aci}^{-}$colonies was observed in the diploids of the mutant ER24 and chromosome X or XII tester strains, indicating that ER24 was located on one of these two chromosome (not shown).

\section{Proton extrusion test}

When cells of the wild-type strains D27310B/A1 or F87-24B were suspended in distilled water, the $\mathrm{pH}$ remained at a constant level of 5 to 6 . Addition of glucose led to a decrease of $\mathrm{pH}$ (Fig. $1 \mathrm{a}$ and $\mathrm{b}$ ). A further decrease of $\mathrm{pH}$ was stimulated by addition of potassium ions.

The same experiment was carried out with the ER24 mutant (Fig. 1c). In this case addition of yeast cells to distilled water led to an abrupt decrease of $\mathrm{pH}$, and the following addition of glucose or potassium ions was without effect.

Acidification by the ER24 mutant without glucose addition does not occur at the cost of endogenous substrates as starvation for $16 \mathrm{~h}$ does not deprive the mutant of the acidification ability (not shown).

The glucose-independent acidification cosegregated with the $\mathrm{Aci}^{+}$character as shown in Fig. 1.d-h. According to the recesiveness of the aci mutations the heterozygous diploid excretes protons upon glucose addition although some abrupt decrease of $\mathrm{pH}$ immediately after addition of yeast cells to distilled water is also observed. In the tet$\mathrm{rad}$, the two $\mathrm{Aci}^{+}$spore clones extruded protons upon addition of water and glucose had no effect. The two Aci- spores excrete acids upon glucose addition although as in the case of the diploid, the addition of water alone cause some slight abrupt $\mathrm{pH}$ decrease.

\section{Isolation and cloning of genes complementing the mutant phenotype of ER24}

In order to isolate genes restoring wild-type (Aci-) phenotype in the ER24 mutant we used a yeast bank gene library on multicopy plasmid pFL44L obtained thanks to courtesy of Dr. Francois Lacroute (Gif-sur-Yvette, France).

The $\Delta$ ura3 marker was incorporated by recombination into the mutant used a recipient in the transformation. The recombinant acil $\Delta$ ura3 cells were transformed with the DNA bank and the transformants ER24 selected for Ura prototrophy were screened for the Aci- phenotype. Three transformants of ER24 were isolated and designated tER24-1, -2 and -3.

\section{Test of mitotic segregation}

In order to check the stability of the plasmids carrying the genes restoring the $\mathrm{Aci}^{+}$phenotype, mitotic segregation of the transformed markers was determined.

After about 24 generations on complete medium (without selective pressure) approx. $80 \%$ of 
a)

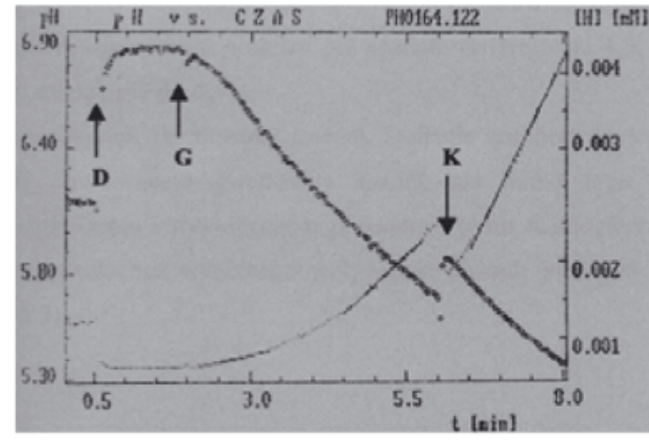

D273-10B/A

c)

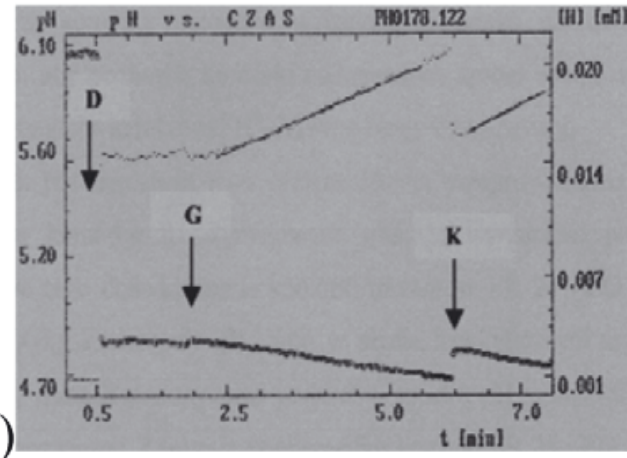

ER24

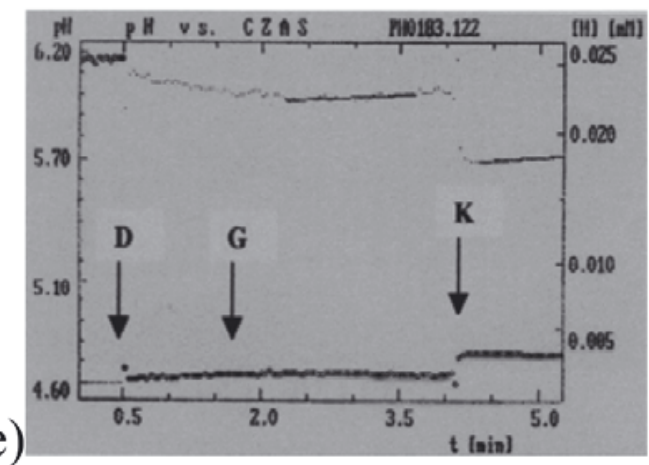

spore $1 \mathrm{~A} \mathrm{Aci+}$

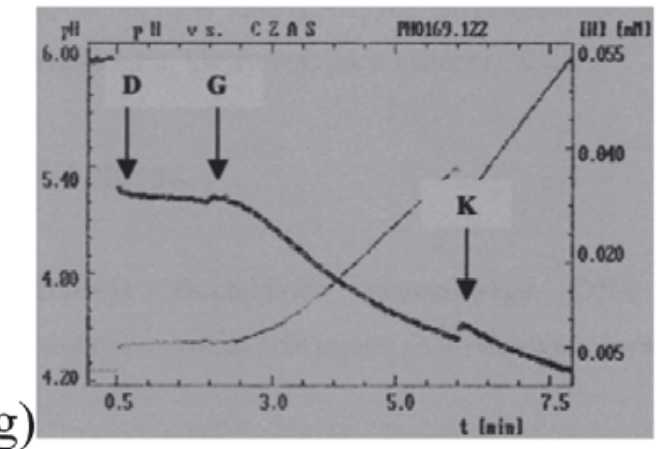

spore 1C Aci- b)

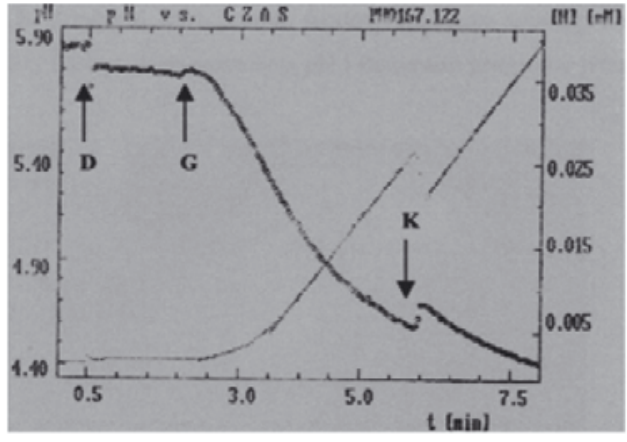

F87-24B

d)

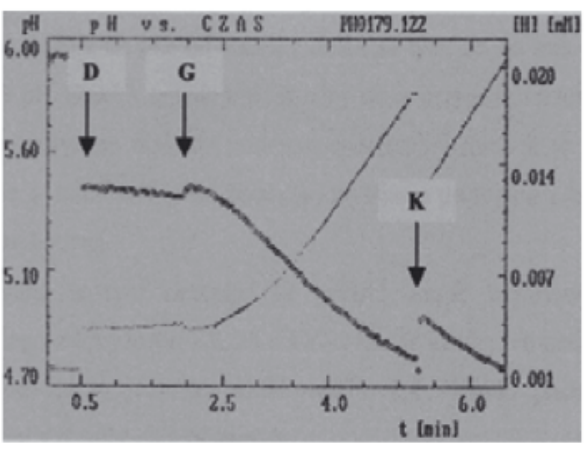

ER24 x F87-24B

f)

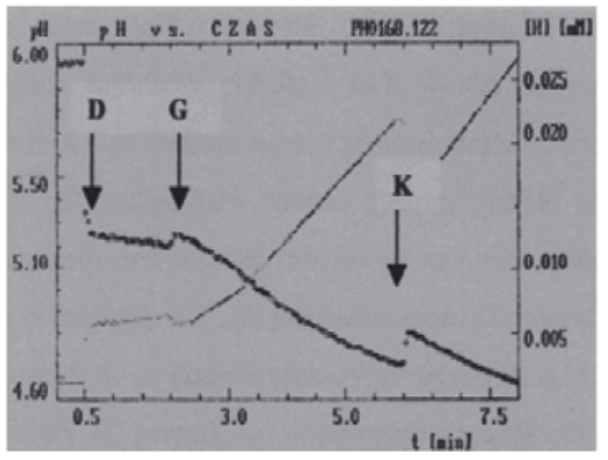

spore 1B Aci-

h)

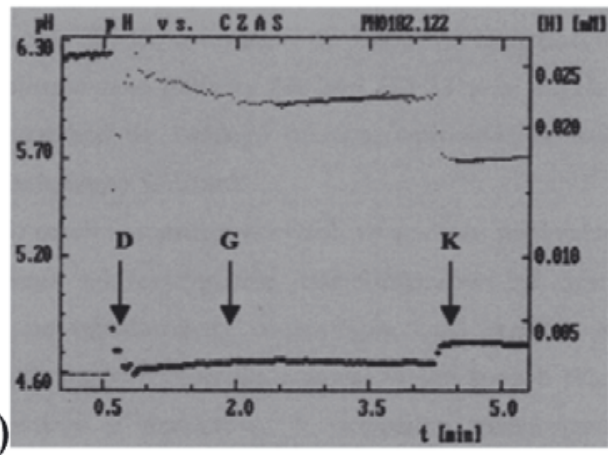

spore 1D Aci+

Figure 1. Acidification traces after successive addition of yeast cells (D) from the original strain D273-10B/A $(a)$, the isogenic strain F87-24B (b), the ER24 mutant (c), the diploid ER24 x F87-24B (d), the spore clones of the tetrad (e, spore1A Aci ${ }^{+}$; f, spore1B Aci-; g, spore1C Aci-; h, spore 1D $\mathrm{Aci}^{+}$), $50 \mathrm{mM}$ glucose (G) or $20 \mathrm{mM} \mathrm{KCl} \mathrm{(K)} \mathrm{to} \mathrm{distilled}$ water. 
Table 3. Phenotypes of transformants of non-allelic mutants from different complementation groups with multicopy genes YJL185C, YLR376C and YJR129C

\begin{tabular}{|c|c|c|c|c|c|c|c|c|c|c|c|c|c|c|c|c|c|}
\hline \multicolumn{18}{|c|}{ Aci phenotype of transformant obtained from mutants: } \\
\hline $\begin{array}{l}\text { Com- } \\
\text { plemen- } \\
\text { tation } \\
\text { group }\end{array}$ & I & II & III & IV & V & VI & VII & VIII & IX & $x$ & XI & XII & XIII & XIV & $X V$ & XVI & XVII \\
\hline $\begin{array}{l}\text { Aci- }^{-} \\
\text {Mutants }\end{array}$ & EG7 & EG13 & ER24 & EG37 & EG40 & EG47 & EG74 & EG77 & EG84 & EG87 & EG85 & EG43 & EG51 & EG8 & EG20 & EG30 & EG16 \\
\hline Genes aci & & & & & & & & & & & & & & & & & \\
\hline YJR129C & $\mathrm{Aci}^{-}$ & Aci $^{-}$ & $\mathrm{Aci}^{-}$ & $\mathrm{Aci}^{-}$ & $\mathrm{Aci}^{-}$ & $\mathrm{Aci}^{-}$ & 0 & $\mathrm{Aci}^{-}$ & $\mathrm{Aci}^{+}$ & $\mathrm{Aci}^{-}$ & $\mathrm{Aci}^{+}$ & $\mathrm{Aci}^{+}$ & $\mathrm{Aci}^{+}$ & $\mathrm{Aci}^{+}$ & Aci $^{-}$ & $\mathrm{Aci}^{+}$ & $\mathrm{Aci}^{-}$ \\
\hline YJL185C & $\mathrm{Aci}^{-}$ & $\mathrm{Aci}^{+}$ & $\mathrm{Aci}^{-}$ & $\mathrm{Aci}^{-}$ & $\mathrm{Aci}^{+}$ & 0 & $\mathrm{Aci}^{-}$ & $\mathrm{Aci}^{-}$ & $\mathrm{Aci}^{+}$ & 0 & $\mathrm{Aci}^{+}$ & $\mathrm{Aci}^{+}$ & $\mathrm{Aci}^{+}$ & $\mathrm{Aci}^{+}$ & $\mathrm{Aci}^{+}$ & $\mathrm{Aci}^{+}$ & $\mathrm{Aci}^{-}$ \\
\hline YJR376C & $\mathrm{Aci}^{-}$ & $\mathrm{Aci}^{-}$ & $\mathrm{Aci}^{-}$ & $\mathrm{Aci}^{-}$ & $\mathrm{Aci}^{-}$ & $\mathrm{Aci}^{-}$ & $\mathrm{Aci}^{-}$ & $\mathrm{Aci}^{-}$ & $\mathrm{Aci}^{+}$ & $\mathrm{Aci}^{-}$ & $\mathrm{Aci}^{+}$ & $\mathrm{Aci}^{+}$ & $\mathrm{Aci}^{+}$ & $\mathrm{Aci}^{+}$ & $\mathrm{Aci}^{+}$ & $\mathrm{Aci}^{+}$ & $\mathrm{Aci}^{+}$ \\
\hline
\end{tabular}

the cells retained the complete plasmids. This indicates that the transformants were rather stable.

\section{Sequencing and identification of yeast genome fragments}

Plasmid DNA was isolated from the transformants. The plasmids were cloned in E. coli strain $\mathrm{DH} 5 \alpha$ and for each yeast transformant three bacterial clones were isolated. The plasmids were restriction mapped with EcoRI and HindIII. For further investigation we chose three plasmids that differed in restriction maps (pER24-1/No1, pER24-3/No1, pER24-3/No2). After retransformation of the plasmids chosen into the ER24 strain, one hundred of transformants obtained (selected for Ura prototrophy) appeared $\mathrm{Aci}^{-}$.

The fragments of the yeast genome carried on the plasmids were cut out, separated by
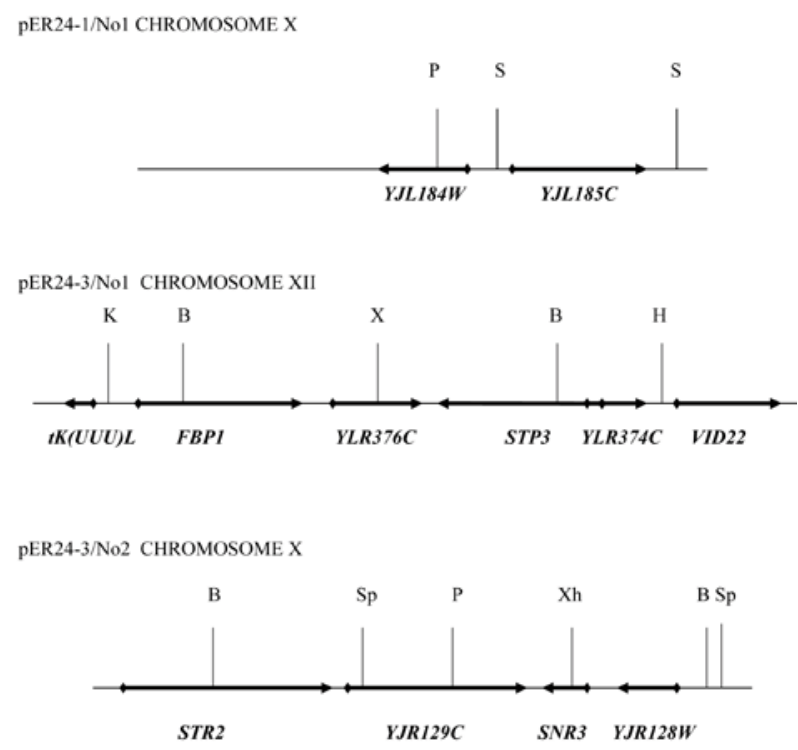

Figure 2. Molecular map of the genes restoring the wild phenotype in the ER24.

Restriction enzymes and cut sites: P (PvuII), S (SalI), K $(K p n \mathrm{I}), \mathrm{B}(\mathrm{BamHI}), \mathrm{X}(\mathrm{XbaI}), \mathrm{H}$ (HindIII), Sp (SphI), Xh (XhoI). electrophoresis and their $3^{\prime}$ and $5^{\prime}$ ends were sequenced. The obtained nucleotide sequences were identified using the BLAST program (Altschul et al., 1990).

Plasmid tER24-1/No1 contained a 3638 bp fragment from chromosome $X$ (81639 to 85276) with ORFs: YJL185C (hypothetical ORF), and YJL184W (hypothetical ORF) (Fig. 2).

Plasmid tER24-3/No1 contained a 5964 bp fragment from chromosome XII (876262 to 870299) with ORFs: tK(UUU)L (tRNA), YLR377C (FBP1 - fructose-bisphosphatase), YLR376C (hypothetical ORF), YLR375W (STP3 - involved in pre-tRNA splicing and in uptake of branched-chain amino acids), YLR374C (hypothetical ORF), and YLR373C (VID22 - glycosylated integral membrane protein localized to the plasma membrane) (Fig. 2).

Plasmid tER24-3/No2 contained a 5415 bp fragment from chromosome $X$ (667453 to 662038) with ORFs: YJR128W (hypothetical ORF), SNR3 (small nucleolar RNA), YJR129C (hypothetical ORF) and YJR130C (STR2 - cystathionine gamma-synthase) (Fig. 2).

\section{Identification of the gene(s) restoring wild-type phenotype in the ER24 mutant}

As cloned, the yeast genomic fragment of plasmid tER24-1/No1 restoring the wild-type $\mathrm{Aci}^{-}$phenotype contained two complete genes. In order to determine which of these genes is responsible for the suppression, we successively cut out the genes YJL184W and YJL185C with the restriction enzyme SalI (Fig. 2), inserted them into empty plasmid pFL44L and transformed the ER24 mutant (Table 2). The $\mathrm{Aci}^{-}$(wild-type) phenotype was found only in transformants that obtained the YJL185C gene.

As cloned, the yeast genomic fragment of plasmid tER24-3/No1 restoring the wild-type $\mathrm{Aci}^{-}$phenotype contained six genes: $t K(U U U) L, F B P 1, Y L R 376 C$, STP3, YLR374C and VID22 (Table 2, Fig. 2) and inserted them separately into empty plasmid pFL44L. In 
order to determine which of them was responsible for the suppression, we successively cut out the genes with restriction enzymes (Fig. 2). Out of the four constructs obtained only one with the YLR376C gene restored the wild-type $\mathrm{Aci}^{-}$phenotype in the ER24 mutant.

Plasmid pER24-3/No2 restoring the wild-type Aci- $^{-}$phenotype in ER24 contained yeast DNA carrying four genes: STR2, YJR129C, SNR3 and YJR $128 \mathrm{~W}$ (Fig. 2). The genes were separately subcloned in pFL44L. Restoration of the wild-type phenotype was obtained only with the plasmid carrying the YJR129C gene (Fig. 2).

\section{Disruption of the YJL185C, YLR376C and YJR129C genes}

Each of the genes restoring the wild-type phenotype in ER24, YJL185C, YLR376C and YJR129C, was disrupted in the wild-type strain. The disruptants (from Euroscarf) were unable to grow on glycerol and produced the acid yellow halo on Kok medium. In the liquid acidification test, each mutant extruded protons without glucose stimulation. The disruptants were recessive as they gave wildtype Aci- diploids when crossed with the wild-type strain $\mathrm{D} 273-10 \mathrm{~B} / \mathrm{A}_{1}$. In the diploids the phenotype of abrupt proton extrusion in the absence of glucose gave monogenic 2:2 segregation. In other words, they showed the typical mutated $\mathrm{Aci}^{+}$phenotype.

The suppression appears non-specific as each of the wild type genes YJL185C, YLR376C and YJR129C on a multicopy plasmid restored the $\mathrm{Aci}^{-}$ wild-type phenotype in several other non-allelic aci mutants (Table 3). This will be explained in more detail in a next publication.

In order to determine which of the three genes is allelic to ER24 (aci1) mutation, we carried out complementation experiments with three disruptants. The disruptants, named YJL185C, YLR376C and YJR129C, were crossed with the original ER24 mutant and the obtained diploids were tested for the acidification phenotype. One of the analyzed diploids, ER24 $x$ YLR376, was Aci indicating allelism of YLR376 with the ER24 mutant aci1 gene. To confirm this finding, the YLR376 gene was introduced into the centromeric plasmid pFL38 and the original ER24 mutant was transformed with the obtained construct. The resulting transformant was $\mathrm{Aci}^{-}$, as expected. The other two genes (YJL185C and YJR129C) when similarly tested, appeared to be multicopy, but not single-copy, suppressors of the mutant $\mathrm{Aci}^{+}$phenotype.

\section{DISCUSSION}

The aci1 mutant ER24 was transformed with a genomic DNA library on the multicopy shuttle plas- mid pFL44L. We found that transformants carrying the YJL185C, YLR376C or YJR129C genes from chromosomes X, XII and X, respectively, restored the wild-type Aci- phenotype in the ER24 mutant.

The suppression is unspecific as each of this three genes restores the wild-type phenotype of many other non-allelic aci mutants. When disrupted in a wild-type strain, each of the genes gives the $\mathrm{Aci}^{+}$phenotype and prevents growth on glycerol. According to the test of complementation one of these genes appeared allelic with the ER24 mutation. The other two genes appeared to be multicopy suppressors of the ER24 mutant $\mathrm{Aci}^{+}$phenotype.

Their function is far from being fully understood. Out of several possibilities considered also in our previous publication (Machnicka et al., 2002) we propose the following two most likely interpretations. Either the multicopy suppressors modify the components of the cellular membrane in such a way that leakage of acid intermediates is prevented or they function in a complex regulatory mechanism that turns on the glyoxylic acid cycle when the keto acid substrates for amino acid synthesis are not required. The second possibility may be more likely, at least for the YLR376C and YJR185C genes. Indeed, while Yj1129Cp is still of unknown function, recent evidence suggests possible regulatory functions for Ylr185Cp either in chromatin action or in protein trafficking and for Yjr376Cp at the level of DNA maintenance. The protein Ylr185Cp is a putative methyltransferase. Its expression is drastically increased in Histone 4 mutants and this protein may be involved in microtubule biogenesis as a member of the folding of a prechaperone complex (Huh et al., 2003). Ylr376Cp/Psy3p has been reported to be part of a large novel protein complex involved in error-free DNA repair (Shor et al., 2005). How such proteins may regulate the expression and or activity of the glyoxilic and tricarboxilate cycles remains to be determined. The described genes seem to represent a new family of genes encoding a new family of proteins.

\section{Acknowledgements}

We would like to thank Professor A. Goffeau for critical review of the manuscript.

S.U. and R.W. are supported by a grant (PBZMin-015/P0/2004) from the Ministry of Education and Science.

\section{REFERENCES}

Altschul SH, Gish W, Miller W, Myers W, Lipman J (1990) Basic local aligment search tool. J Mol Biol 215: 403410. 
Boniewska-Bernacka E, Lachowicz TM, Kotylak Z (1998) Genetical and biochemical characterization of Krebs cycle mutants in yeast. Acta Microbiol Polon 47: 131-140.

Bonneaud N, Ozier-Kalogeropoulos O, Li G, Labouesse M, Minvielle-Sebastia L, Lacroute F (1991) A family of low and hight copy replicative, integrative and single-stranded S. cerevisiae/E. coli shutte vectors. Yeast 7: 609-613.

Claisse M, Lachowicz TM, Sybirny A, Gonchar M, Boniewska E, Witkowska R (1992) Isolation and characterization of Krebs cycle mutants of yeast Saccharomyces cerevisiae. Yeast 8: 105.

Gietz RD, Woods RA (1998) Transformation of yeast by the lithium acetate/single-stranded carrier DNA/PEG method. Methods Microbiol 20: 53-66.

Goffeau A (2000) Four years of post-genomic life with 6000 yeast genes. FEBS Lett 480: 37-41.

Gonchar M, Lachowicz TM, Sybirny A, Witkowska R, Zakowska Z (1990) Genetics, physiology and biochemistry of some Saccharomyces cerevisiae mutants excreting acidic products. In Genetics of Respiratory Enzymes in Yeast. pp 53-64. Wroclaw University Press, Wrocław.

Grochowalska R, Machnicka B, Wysocki R, Lachowicz TM (2003) The genetic characteristics Saccharomyces cerevisiae aci(+) mutants. Cell Mol Biol Lett 8: 261-268.

Hanahan D (1983) Studies on transformation of Escherichia coli with plasmids. J Mol Biol 166: 557-580.

Haworth R, Lemire B, Crandall D, Cragoe E, Fliegel L (1991) Characterization of proton fluxes across the cytoplasmic membrane of the yeast Saccharomyces cerevisiae. Biochim Biophys Acta 1089: 78-89.

Huh WK, Falvo JV, Gerke LC, Carroll AS, Howson RW, Weissman JS, O'Shea EK (2003) Global analysis of protein localization in budding yeast. Nature 425: 686-691.

Kok J, Muller JL, Slater EC (1975) EPR studies on the respiratory chain of wild type Saccharomyces cerevisiae and mutants with deficiency in succinate dehydrogenase. Biochim Biophys Acta 912: 441-450.

Machnicka B, Grochowalska R, Lipiński T, Boniewska E, Słomińska L, Lachowicz TM (2002) An identification of the products excreted by Saccharomyces cerevisiae aci ${ }^{+}$ mutants (acidifying growth media). Cell Mol Biol Lett 7: 304.

Machnicka B, Grochowalska R, Boniewska-Bernacka E, Słominska L, Lachowicz TM (2004) Acid excreting mutants of yeast Saccharomyces cerevisiae. Biochem Biophys Res Commun 325: 1030-1036.

Radomski R, Radomska M, Szajnowska K, Wisialski Z (1995) Microcomputer-controlled electrochemical universal meter. Computers Chem Res 7: 40-46.

Sambrook J, Fritsch EF, Maniatis T (1989) Molecular Cloning. A Laboratory Manual. 2nd edn, Cold Spring Harbor Laboratory Press, Cold Spring Harbor, New York.

Sanger F, Nicklen S, Coulson A (1977) DNA sequencing with chain-terminating inhibitors. Proc Natl Acad Sci USA 74: 5463-5467.

Sherman F, Fink GR, Hicks JB (1987) Methods in Yeast Genetics. Cold Spring Harbor Laboratory Press, Cold Spring Harbor NewYork.

Shor E, Weinstein J, Rothstein R (2005) A genetic screen for top3 suppressors in Saccharomyces cerevisiae identifies SHU1, SHU2, PSY3 and CSM2: Four genes involved in error-free DNA repair. Genetics 169: 1275-1289.

Sigler K, Hofer M (1991) Mechanism of acid extrusion in yeast. Biochim Biophys Acta 1071: 375-391.

Sigler K, Knotkova A, Kotyk A (1981) Factors governing substrate induced generation and extrusion of protons in the yeast Saccharomyces cerevisiae. Biochim Biophys Acta 643: 572-582.

Wakem L, Sherman F (1990) Chromosomal assignment of mutations by specific chromosome loss in the yeast Saccharomyces cerevisiae. Genetics 12: 333-340. 